\title{
Breast conserving surgery with preservation of the nipple-areola complex as a feasible and safe approach in male breast cancer: a case report
}

\author{
Sophocles Lanitis*, George Filippakis ${ }^{\dagger}$, Ragheed Al Mufti ${ }^{\dagger}$ and \\ Dimitri J Hadjiminas ${ }^{\dagger}$
}

Address: Breast Care Unit, Mary Stanford Wing 5th Floor, St Mary's NHS Trust, Praed Street, London W2 1NY, UK

Email: Sophocles Lanitis* -drlanitis@yahoo.com; George Filippakis - gfilipp@hotmail.com; Ragheed Al Mufti - ralmufti@doctors.org.uk; Dimitri J Hadjiminas - dhadjiminas@breastsurgeon.co.uk

* Corresponding author †Equal contributors

\author{
Published: 28 April 2008 \\ Received: 14 September 2007 \\ Journal of Medical Case Reports 2008, 2:126 doi:10.1186/1752-1947-2-126 \\ Accepted: 28 April 2008 \\ This article is available from: http://www.jmedicalcasereports.com/content/2/I//26 \\ (C) 2008 Lanitis et al; licensee BioMed Central Ltd. \\ This is an Open Access article distributed under the terms of the Creative Commons Attribution License (http://creativecommons.org/licenses/by/2.0), \\ which permits unrestricted use, distribution, and reproduction in any medium, provided the original work is properly cited.
}

\begin{abstract}
Introduction: Breast cancer in men is rare. The evidence about treatment has been derived from data on the management of the disease in women. The usual treatment is for male patients to undergo modified radical mastectomy. There is insufficient experience of breast conserving surgery with preservation of the nipple. The management of patients who demand such an approach for personal reasons remains a challenge for both the surgeon and oncologist.

Case presentation: A 50-year-old man with a breast cancer was successfully managed with breast conserving surgery with nipple preservation combined with axillary clearance and postoperative radiotherapy, chemotherapy and hormone treatment. Since there are no similar cases in the literature, we discuss the feasibility, safety and possible indications of such an approach.

Conclusion: Despite the limited indications and evidence about the safety and efficacy of breast conserving surgery with nipple preservation in men with breast cancer, it is a feasible approach if other options are declined by the patient. More studies are necessary to reach firm conclusions about the safety of such an approach.
\end{abstract}

\section{Introduction}

Male breast cancer (MBC) is a rare disease and accounts for less than $1 \%$ of breast cancers but incidence seems to be increasing [1-6]. Owing to the small number of cases, management of MBC is based on evidence derived from data analysis of female breast cancer (FBC) patients and on retrospective studies of a limited number of $\mathrm{MBC}$ patients $[2,3,5]$. There is little experience of breast conserving surgery (BCS) with nipple preservation, as usually there is no interest for the treatment from either the surgeon or patient. Therefore, management of those patients who demand such an approach remains a challenge for the treating physicians.

\section{Case presentation}

A 50-year-old man was referred to the breast unit presenting with a month's history of a suspicious lump in his left breast. He had no family history of cancer. From his medical history, the only remarkable finding was hepatitis B 30 years previously and genital herpes for which he was taking Acyclovir. He had a history of smoking (30 packs per year). 
Clinically, he had a lump centrally in the left breast, at a 6 o'clock position, with skin tethering and mild inversion of the nipple. Ultrasound (US) and a mammogram demonstrated a $1 \mathrm{~cm}$ suspicious lesion, which was found to be cancer on both fine needle aspiration (FNA) and core biopsy. The tumour was a grade 2 invasive ductal carcinoma (IDC). Investigations did not show any distant metastases. The patient was offered modified radical mastectomy and sentinel node biopsy (SNB). The patient declined any operation that would not preserve the nipple and insisted on having BCS. After discussion with the oncologists and patient about the risk of recurrence, we proceeded with BCS with nipple preservation and SNB. The sentinel node was involved and level III axillary clearance was performed. Overall, one out of nine dissected lymph nodes was positive. Our well-established protocols for wide local excisions rely on $5 \mathrm{~mm}$ pathological clear margins rather than negative margins [7]. Therefore, we do not use frozen sections to assess the surgical margins. The specimen weighed $19 \mathrm{~g}$ and included a $0.7 \times 0.7 \times 1$ $\mathrm{cm}$ grade 2 IDC with an intermediate grade ductal carcinoma in situ (DCIS), comprising $5 \%$ of the tumour mass. The tumour was positive for oestrogen (ER) and progesterone receptors (PgR). The DCIS was present $0.2 \mathrm{~cm}$ from the superficial margin and all other margins were more than $0.8 \mathrm{~cm}$.

The patient had four cycles of chemotherapy (Doxorubicin $100 \mathrm{mg}$ and Cyclophosphamide $1000 \mathrm{mg}$ ) and adjuvant chest wall radiotherapy ( 50 gray in 25 fractions), which he tolerated well. He was commenced on Tamoxifen $20 \mathrm{mg}$ once a day for 5 years and then switched to Letrozole $2.5 \mathrm{mg}$. Repeated followup clinical examinations, mammograms, breast US, bone scans and liver US showed no evidence of disease. Eight years after the operation, the mammogram showed microcalcifications in the ipsilateral breast and he underwent diagnostic biopsy of the area, which showed fibrofatty tissue with focal stromal calcifications without features of malignancy.

\section{Discussion}

MBC behaves in a way similar to FBC in postmenopausal women [6]. Unlike FBC, there is only one peak at 67-71 years of age $[2,4,6]$. Family history, genetic factors (for example, BRCA gene carriers, AR and CYP17 gene mutation, Klinefelter syndrome, Cowden syndrome), exogenous oestrogen administration and testicular anomalies are among the risk factors $[1-4,6]$, while radiation, obesity and alcohol use are proposed but not widely accepted as risk factors $[2,3,6]$. There is no proven association between gynaecomastia and MBC $[4,6]$. Histologically, more than $85 \%$ of tumours are of the invasive ductal type [4,6]. Furthermore, over $90 \%$ of MBC express ER while $81 \%$ express PgR $[5,8]$. C-erb-B2 is less likely to be expressed (about $5 \%$ ) [2,3]. In men, $20 \%$ of the circulat- ing estrogen is produced by the testis while about $80 \%$ results from peripheral aromatisation of androgens $[3,9]$. The usual presentation is a palpable painless lump with or without skin changes or nipple involvement but often diagnosis is delayed $[4,6]$. The sensitivity of the mammogram is reported to be $92 \%$ while specificity is $90 \%$ [6]. Breast US can be used to evaluate the tumour in the same way as in women $[2,4,10]$. The prognosis depends on tumour size, grade and extent of lymph node involvement in the same way as in $\mathrm{FBC}[2,6]$. Overall survival rate when corrected for age is similar to that of FBC $[2,6]$.

Traditionally patients with MBC undergo modified radical mastectomy with either SNB or axillary node clearance (ANC) $[2,3,6]$. Despite the lack of firm evidence about the safety of $\mathrm{SNB}$, increasingly there is an acceptance of the technique and its use $[2,6]$. Radiation therapy seems to prevent local recurrence but it is not known whether it adds anything to survival. The indications and dose remain the same as in women $[2,6]$. Ablative techniques aiming to control hormones, including orchidectomy, adrenalectomy and hypophysectomy, have been used in the past but had severe side effects, therefore medical hormone manipulation has been tried $[3,5]$. For those patients with hormone receptor-positive tumours, there is a clear benefit from the use of Tamoxifen in both diseasefree and overall survival $[3,5,6,11,12]$. There is also a proven effectiveness in those patients with metastatic disease and, therefore, Tamoxifen has been incorporated in the treatment of MBC $[2,3,5,11]$. There is not sufficient evidence for the use of aromatase inhibitors despite the advances and proven efficacy in FBC and more studies need to be done $[2,3,5]$. There are case reports supporting a good response to Letrozole $[3,13]$ even after failure of Tamoxifen [3]. There is also some evidence about the effectiveness of adjuvant chemotherapy. One prospective study with a small number of patients $(N=24)$ showed a survival benefit and other studies support this finding [14]. Moreover, retrospective studies show reduction of the risk of local recurrence $[2,6,15]$.

\section{Conclusion}

Despite limited indications and lack of evidence about the safety and efficacy of BCS with nipple preservation in men with breast cancer, it is a feasible approach if other options are declined by the patient. Apparently obtaining good excision margins is the most important predictor of local recurrences as it is for women.

With a case report of only one patient, it is impossible to make any statement about the safety of such an approach and more studies are necessary to reach firm conclusions. 


\section{Abbreviations}

ANC: axillary node clearance; BCS: breast conserving surgery; DCIS: ductal carcinoma in situ; FBC: female breast cancer; FNA: fine needle aspiration; IDC: invasive ductal carcinoma; MBC: male breast cancer; SNB: sentinel node biopsy; US: ultrasound.

\section{Competing interests}

The authors declare that they have no competing interests.

\section{Authors' contributions}

SL and GF collected the data and reviewed the literature and case notes and was involved in followup appointments. Furthermore, SL was involved in the active followup and workup of the patient. SL wrote the paper with the assistance of GF. RAM reviewed and edited the initial manuscript. DJH performed the initial operation, and organised the primary management plan of the patient. He supervised the writing and editing of the paper. All the authors have read and approved the final version of the manuscript.

\section{Consent}

Written informed consent was obtained from the patient for publication of this case report and any accompanying images. A copy of the written consent is available for review by the Editor-in-Chief of this journal.

\section{Acknowledgements}

We thank St Mary's Breast Care Unit for secretarial support and Charlotte Garcia from St Mary's radiology department for the imaging supply.

\section{References}

I. Weiss JR, Moysich KB, Swede H: Epidemiology of male breast cancer. Cancer Epidemiol Biomarkers Prev 2005, | 4:20-26.

2. Giordano $\mathrm{SH}$ : $\mathbf{A}$ review of the diagnosis and management of male breast cancer. Oncologist 2005, 10:47|-479.

3. Zabolotny BP, Zalai CV, Meterissian SH: Successful use of letrozole in male breast cancer: a case report and review of hormonal therapy for male breast cancer. J Surg Oncol 2005, 90:26-30.

4. Chen L, Chantra PK, Larsen LH, Barton P, Rohitopakarn M, Zhu EQ, Bassett LW: Imaging characteristics of malignant lesions of the male breast. Radiographics 2006, 26:993-1006.

5. Nahleh ZA: Hormonal therapy for male breast cancer: A different approach for a different disease. Cancer Treat Rev 2006, 32:101-105.

6. Fentiman IS, Fourquet A, Hortobagyi GN: Male breast cancer. Lancet 2006, 367:595-604.

7. Sibbering DM, Galea MH, Morgan DA, Elston CW, Ellis IO, Robertson JF, Blamey RW: Safe selection criteria for breast conservation without radical excision in primary operable invasive breast cancer. Eur J Cancer 1995, 3 IA:2191-2195.

8. Giordano SH, Cohen DS, Buzdar AU, Perkins G, Hortobagyi GN: Breast carcinoma in men: a population-based study. Cancer 2004, I 0 I:5 I-57.

9. Griffin J, Wilson J: Disorders of the testis and the male reproductive system. In Williams Textbook of Endocrinology IOth edition. Edited by: Larsen P, Kronenberg H, Melmed S, Polonsky K. Philadelphia: Saunders; 2003:709-769.

10. Evans GF, Anthony T, Turnage RH, Schumpert TD, Levy KR, Amirkhan RH, Campbell TJ, Lopez J, Appelbaum AH: The diagnostic accuracy of mammography in the evaluation of male breast disease. Am J Surg 2001, I81:96-100.
II. Ribeiro G, Swindell R: Adjuvant tamoxifen for male breast cancer (MBC). Br J Cancer 1992, 65:252-254.

12. Goss $P$, Reid C, Pintilie M: Male breast carcinoma: a review of 229 patients who presented to the Princes Margaret Hospital during 40 years: 1955-1996. Cancer 1999, 85:629-639.

13. Italiano A, Largillier R, Marcy PY, Foa C, Ferrero JM, Hartmann MT, Namer M: Complete remission obtained with letrozole in a man with metastatic breast cancer. Rev Med Interne 2004, 25:323-324.

14. Bagley CS, Wesley MN, Young RC: Adjuvant chemotherapy in males with cancer of the breast. Am J Clin Oncol 1987, 10:55-60.

15. Patel HZ, Buzdar AU, Hortobagyi GN: Role of adjuvant chemotherapy in male breast cancer. Cancer 1989, 64: I583-I585.
Publish with Biomed Central and every scientist can read your work free of charge

"BioMed Central will be the most significant development for disseminating the results of biomedical research in our lifetime. " Sir Paul Nurse, Cancer Research UK

Your research papers will be:

- available free of charge to the entire biomedical community

- peer reviewed and published immediately upon acceptance

- cited in PubMed and archived on PubMed Central

- yours - you keep the copyright

Submit your manuscript here:

http://www.biomedcentral.com/info/publishing_adv.asp
BioMedcentral 